\title{
Subject Matter Expert Evaluation of Multi-Flight Common Route Advisories
}

Karl Bilimoria, Miwa Hayashi, and Kapil Sheth NASA Ames Research Center

AIAA Aviation, Technology, Integration, and Operations Conference

$$
\begin{gathered}
\text { Denver, CO } \\
5-9 \text { June } 2017
\end{gathered}
$$




\section{Outline}

- Background on Multi-Flight Common Routes (MFCR)

- Subject Matter Expert evaluation of MFCR

- Key results

- Conclusions 


\section{Background}

Multi-Flight Common Routes (MFCR) identifies opportunities for delay recovery by refreshing outdated routes

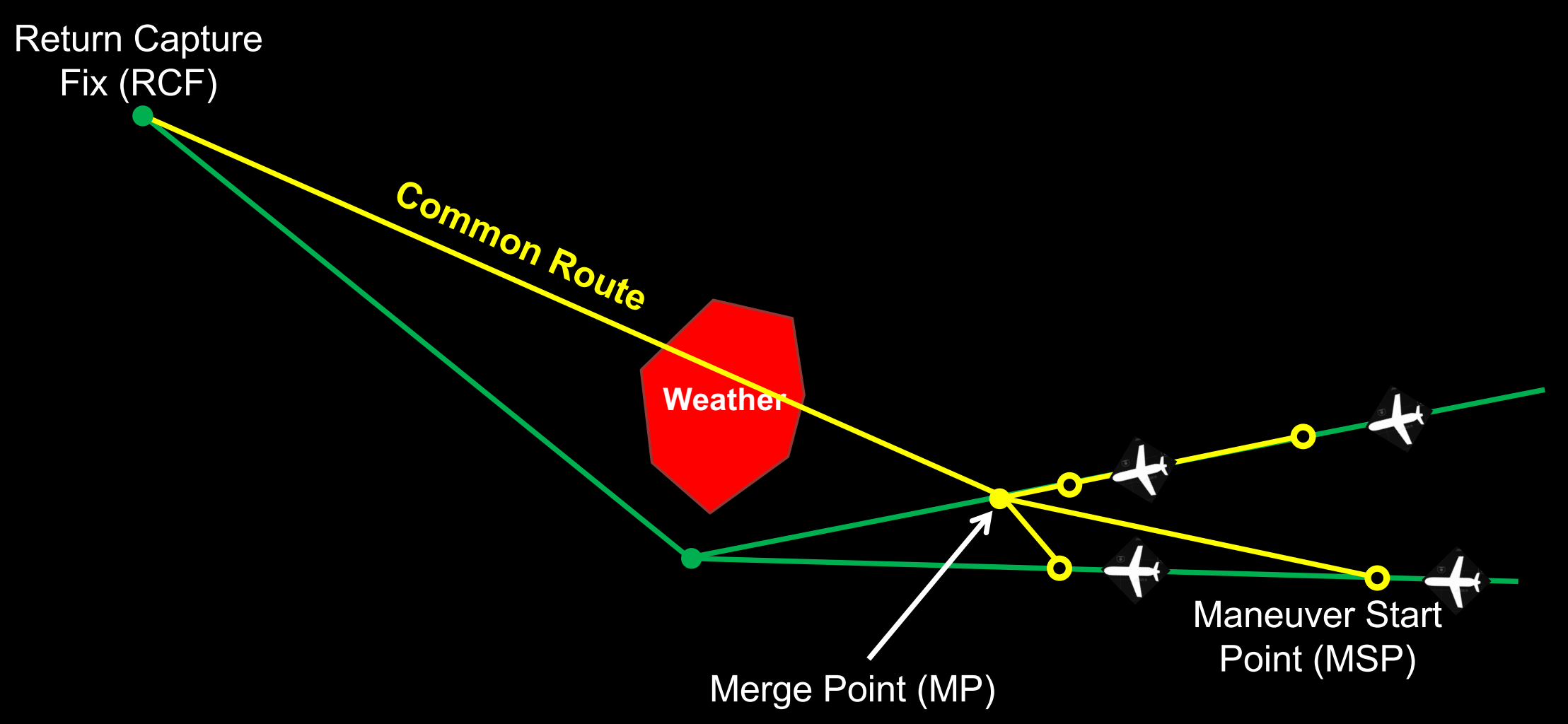




\section{Example MFCR Advisory}

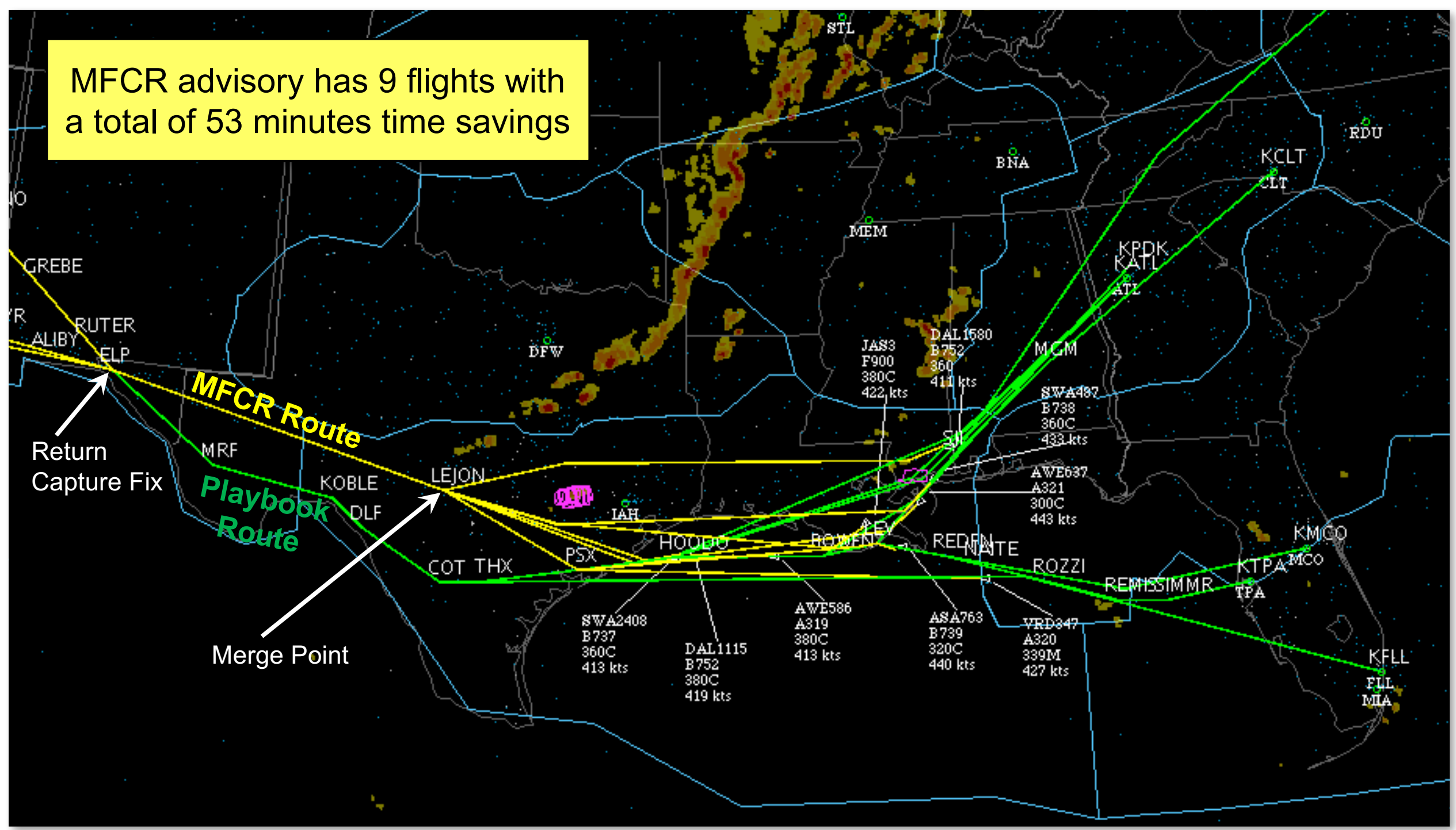




\section{MFCR Features}

- MFCR merges multiple flights to a common route, creating a new flow for increased operational acceptability

- Each route segment is clear of weather

- Each flight has time savings of at least 3 minutes

- Total flight time savings for group is at least 10 minutes

- MFCR provides graphical functionality for review and modification prior to implementation of advisory 


\section{Overview of Evaluation}

- Laboratory evaluation, conducted 1 - 4 Nov 2016

- Five subject matter experts (SMEs) evaluated scenarios in Fort Worth Center (ZFW) \& Houston Center (ZHU) airspace

- SMEs were recently retired traffic managers

- Each SME evaluated 40 scenarios

- Each scenario featured a static MFCR advisory

- Obtained SME feedback on:

- Operational acceptability of MFCR re-route advisories

- Workload and situational awareness

- User interface

- Viability of overall MFCR concept of operations 


\section{MFCR Advisory Parameters}

Houston Center advisories generally featured more flights than Fort Worth Center advisories
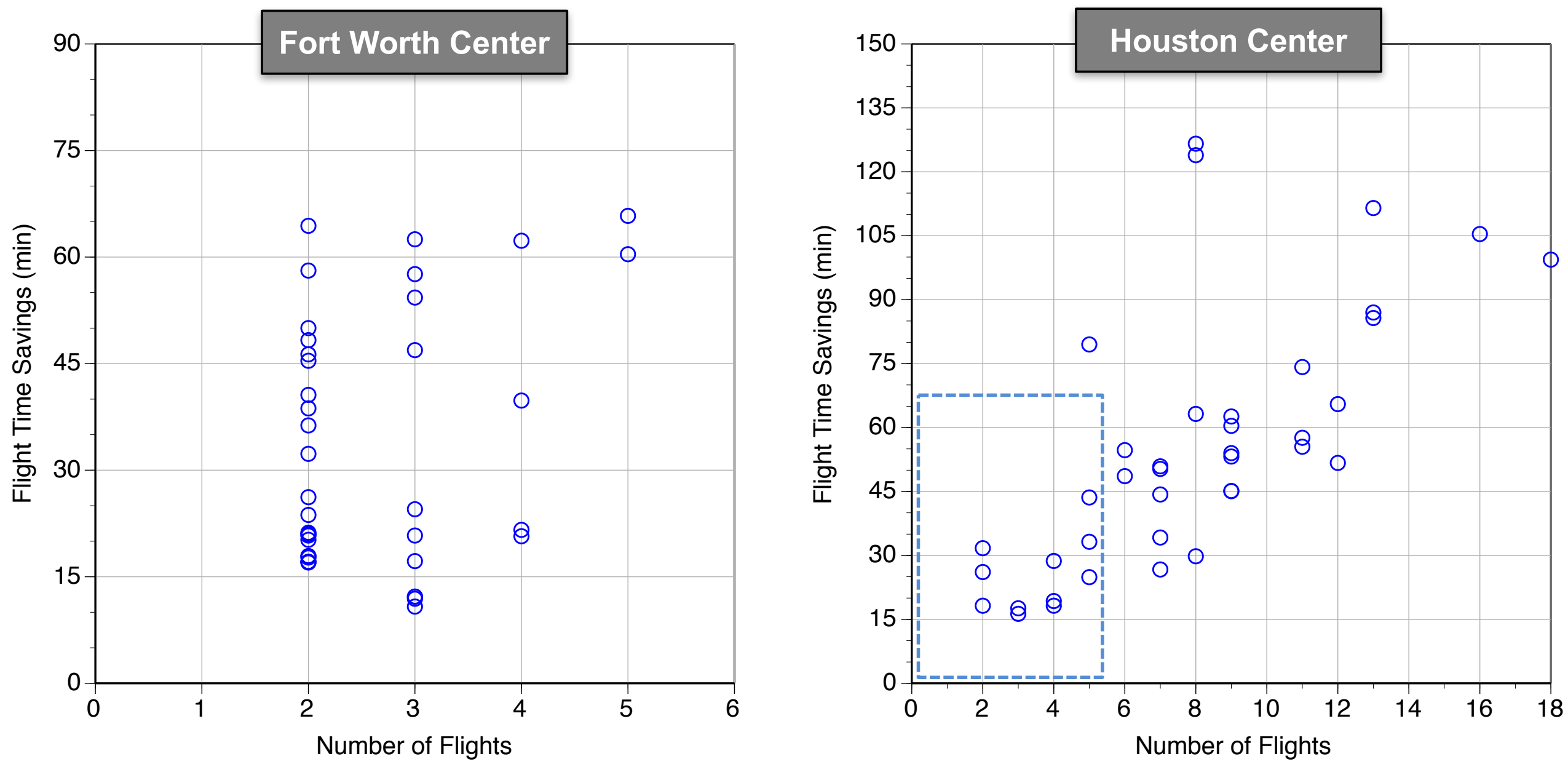


\section{Acceptability Ratings}
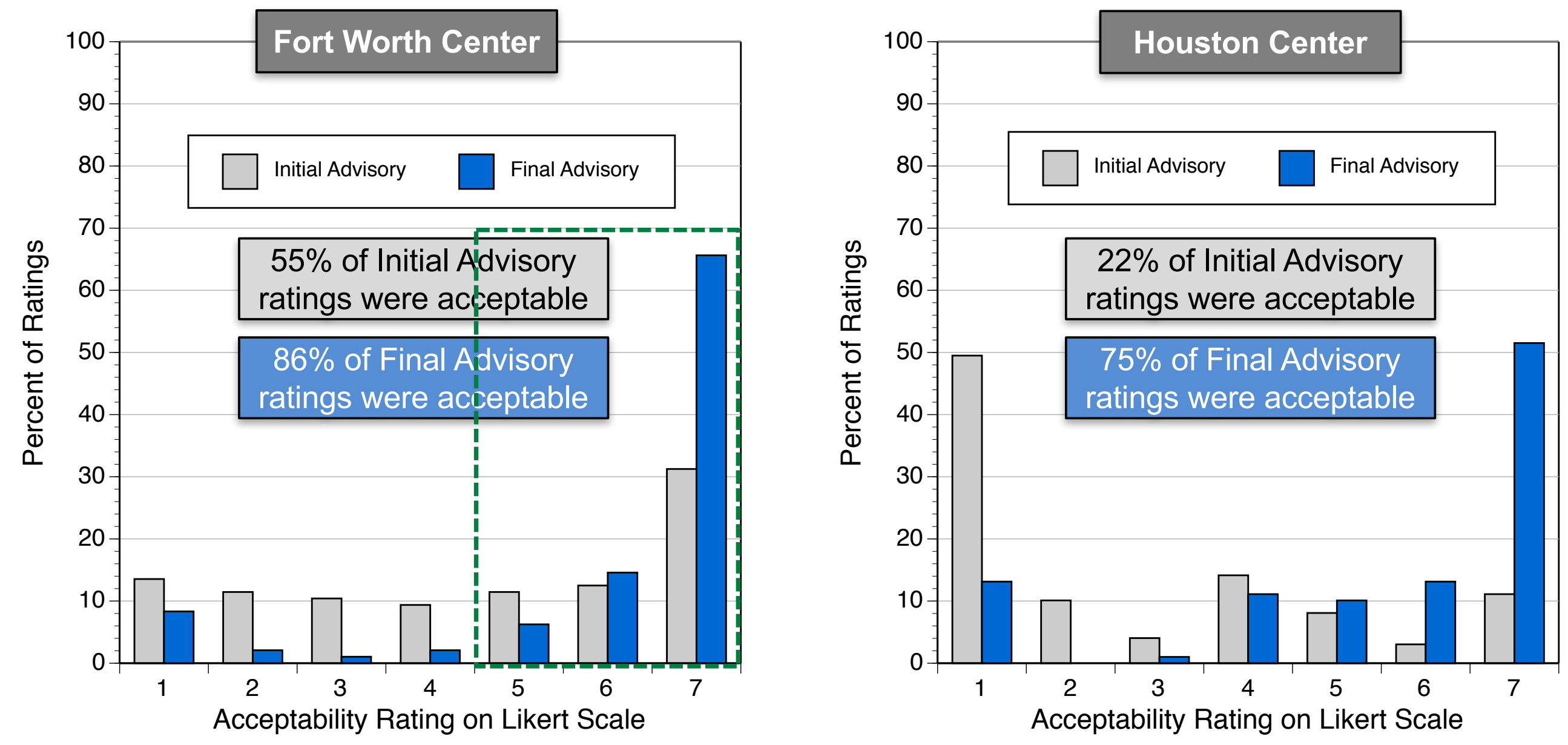


\section{Comments on Acceptability}

- Most advisories that were initially rated as low acceptability were rated as high acceptability after SME modification

- Modifications often corrected undesirable sector traversal

- Route runs close to sector (or Center) boundary

- Route cuts across corner of sector(s)

- Route crosses arrival/departure flows

- Route crosses congested sector(s)

- Route does not conform with standard flow patterns

- User interface provides functionality to quickly/easily make route modifications with feedback on performance measures 


\section{Workload Ratings}
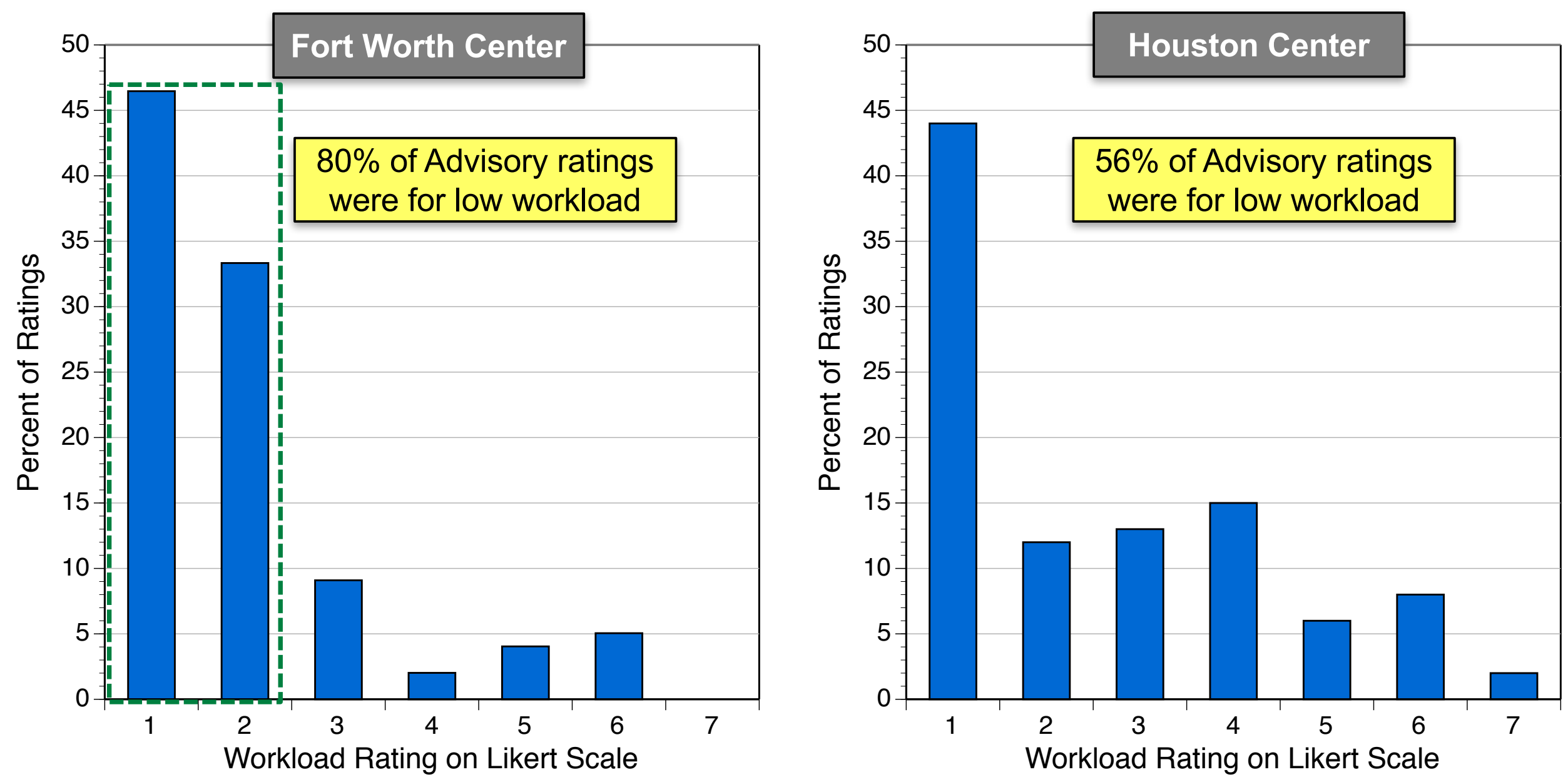


\section{Situational Awareness Ratings}
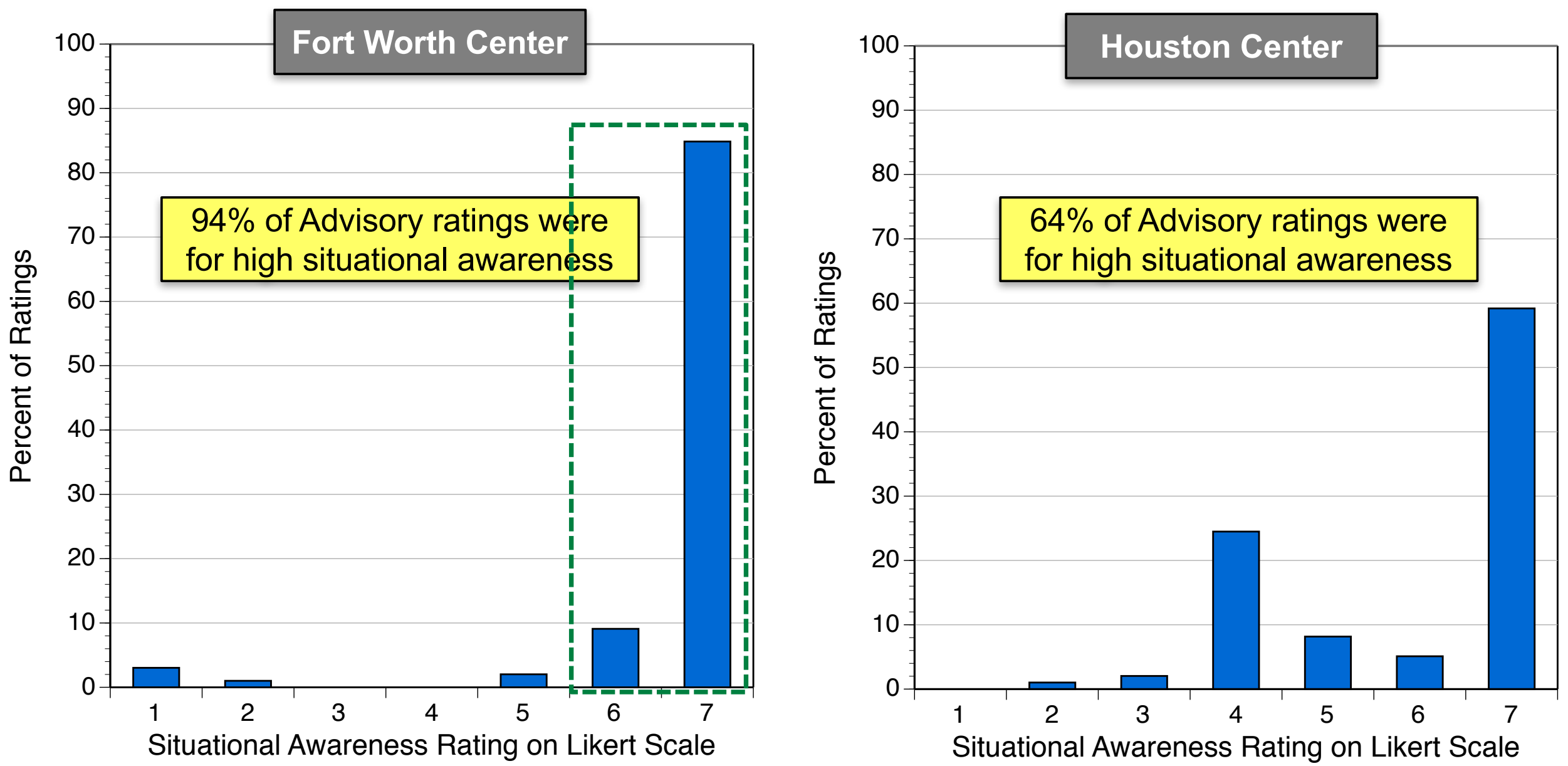


\section{Conclusions}

- MFCR received favorable evaluation from SMEs

- Good acceptability of final/modified MFCR advisories: $86 \%$ for ZFW and $75 \%$ for ZHU

- Low workload to evaluate and modify MFCR advisories: $80 \%$ for ZFW and $56 \%$ for ZHU

- MFCR user interface provides good situational awareness: $94 \%$ for ZFW and $64 \%$ for ZHU

- MFCR is a good example of human-automation teaming 


\section{Questions?}

karl.bilimoria@nasa.gov 